Katja Šmid

Ljubljana

\title{
LOS PROBLEMAS DEL ESTUDIO DE LA LENGUA SEFARDÍ
}

\section{Introducción}

Aunque el estudio sobre la lengua sefardí sin duda pertenece a la investigación en el campo de la filología hispánica, muchas veces se olvida exponer los problemas que atañen este tema. Al investigar la lengua sefardí desde el punto de vista de un hispanista en Eslovenia, nos enfrentamos con distintas dificultades, por eso pretendo repasar algunos hechos conocidos sobre el tema, destacar los principales problemas existentes, exponer diferentes enfoques del estudio del tema y presentar algunas teorías recientes sobre la lengua sefardí.

\section{Sefarad, Sefardí}

Distintas fuentes afirman que la palabra Sefarad en hebreo significa España. Muhamed Nezirović (1992: 11) indica que el nombre S'farad en hebreo significa "el país occidental" y señala que a partir del siglo VIII con el nombre Sefarad se refiere al lugar más occidental de Europa, es decir, la Península Ibérica. Es importante señalar que Sefarad es el nombre con el que los judíos tradicionalmente conocen España o la Península Ibérica.

Sefardí (sustantivo) significa judío oriundo de España o descendiente de los judíos que vivieron en la Península Ibérica antes de su expulsión de 1492.

Sefardí (adjetivo) derivado de ese nombre se aplica a las personas, la lengua, la literatura y la cultura de los judíos descendientes de los que durante la Edad Media, antes de 1492, vivieron en España.

\section{La expansión espacial y temporal de la lengua sefardí}

Los primeros judíos salieron de España en la segunda mitad del siglo XIV (1391), cuando en la Península ya se respiraba el clima de hostilidad antisemita. En 1492, los Reyes Católicos, Fernando e Isabel, decretaron la expulsión de los judíos de España.

Tras la expulsión, algunos grupos de judíos se establecieron en Portugal, de donde fueron expulsados en 1497. Para la lengua que hablaron se utiliza también el término judeoportugués. Muchos de ellos se instalaron en los Países Bajos y siguieron en contacto con el mundo hispano hasta la separación de Flandes (1789). Algunos grupos de judíos se establecieron en el sur de Francia. Menos afortunados fueron los que eligieron como destino Navarra, reino independiente hasta 1512 y cuyos monarcas decretaron la expulsión de los hebreos en 1498. Los que salieron por la vía marítima se establecieron en los países del norte de África. La mayoría de los expulsados se dirigió hacia el este. Unos se establecieron en diversas ciudades en Italia (Ferrara, Venecia, etc.). Otro grupo, muy numeroso, fue acogido por el Imperio Otomano y se estableció en los grandes centros 
urbanos (Salónica, Constantinopla, Esmirna), en el territorio de los actuales estados de Turquía, Grecia, Albania, Bulgaria, Rumanía, Yugoslavia, Bosnia, Croacia y Macedonia.

Para ayudar a los judíos dispersos por el mundo Charles Netter fundó en la segunda mitad del siglo XIX, en 1860, la Alliance Israélite Universelle en Francia. Una red de escuelas Alliance Israélite Universelle se estableció por todas las áreas de Sefarad $2^{1}$ (en Turquía, Grecia, Bulgaria, Macedonia, excepto en Bosnia). Como consecuencia, la lengua francesa tuvo una influencia enorme sobre las variantes de la lengua sefardí en los países enumerados.

Durante la Segunda Guerra Mundial murió un número increíblemente alto de sefardófonos así que, a partir de este capítulo de la historia humana, la existencia de la lengua sefardí es discutible.

\section{Denominaciones, definiciones}

La lengua sefardí tiene varias denominaciones, lo que depende del país donde se habla o estudia. Kalmi Baruch (1930: 113-154) es el primer hispanista en la ex-Yugoslavia que estudiaba la lengua sefardí y menciona las denominaciones ladino, romance, judeo-español, español, žudio.

Los sefardíes llaman a la lengua de estos textos (o sea su lengua literaria) 'ladino', y el traducir de los textos hebraicos 'enladinar'.

Parece que esta expresión se usaba también para designar el habla corriente, a diferencia del hebreo que en la vida de los sefardíes siempre fue y es de especial importancia.

En lugar de esta expresión hallamos en la obra ya citada de Moisén Almosnino la denominación de romance. De todos modos, este vocablo no es popular, ya que no se encuentra en esta acepción en ninguna de las variantes judeo-españolas. Al habla corriente de cada día se le llama español o žudio; en Bosnia, jidî́ (Baruch, 1930: 116-117).

También Alica Knezović (1986: 2-153 y 1991: 97-103) hace diferencia entre el judeoespañol escrito y hablado y los caracteriza brevemente. Para la lengua escrita, el son ladino, característicos el arcaísmo, la riqueza del vocabulario, la purificación de los barbarismos y, en la traducción, el uso estricto de la sintaxis hebrea. Por el contrario, la lengua hablada, el judeoespañol, en el Oriente llamado džudézmo, en Bosnia đidjó o simplemente španjol, absorbe mayores influencias de las lenguas del medio en que vivían los sefardíes.

Es imprescindible estudiar también las denominaciones de "los clásicos", entre los cuales el más importante es Max Leopold Wagner que explica el término ladino y señala el uso de la palabra en el más importante texto épico castellano:

Lađino es la lengua española en oposición al hebreo, y, sobre todo, el español de los libros religiosos; enlađinar quiere decir traducir textos hebraicos al español. El pasaje del Poema del Cid, versos 2768-2769:

\footnotetext{
La terminología Sefarad 1, Sefarad 2 y Sefarad 3 es propia de la escuela de Weinreich y se aplica a: Sefarad 1, la España judia medieval, lo judío anterior a la expulsión; Sefarad 2, lo propiamente sefardí, lo judío hispánico posterior a la expulsion; y Sefarad 3, la dispersión secundaria, nacida a raíz de las migraciones de sefardíes a países que no eran de Sefarad.
} 


\section{Quando esta falsedad dizien los de Carrión,}

Un moro latinado bien gelo entendió.

demuestra que ya entonces lađino era el español en oposición al hebreo o árabe. (Wagner, 1990, tomo III: 127).

También menciona la denominación žargón: “... y el judeo-español quedó reducido a ser un žargón, como los judíos mismos lo llaman muchas veces." (Wagner, 1990, tomo III: 122). La denominación se refiere a una especie de coiné (lengua común) sefardí que se formó cuando poco a poco desaparecieron las antiguas diferencias regionales y en la cual los judíos españoles (especialmente comerciantes) se entendían perfectamente.

Un grupo de investigadores del CSIC completa el problema de diferentes maneras:

Coloma Lleal (1992: 1-82) hace una descripción muy concisa de la lengua estudiada:

El judezmo es la peculiar variante hispánica hablada por los sefardíes, es decir, por los judíos que se establecieron en distintas zonas mediterráneas después de la expulsión del suelo peninsular decretada en 1492. Modalidad que es también conocida como sefardí, atendiendo a la denominación genérica de sus hablantes, como judeoespañol, término descriptivo que pone de relieve su adscripción al área lingüística hispana, y como ladino, con el que con frecuencia suelen denominarla sus propios hablantes para diferenciarla del hebreo, y que parte de la tradición medieval según la cual ladinar significaba 'expresarse en romance' o 'traducir al romance'. (Ibídem, 1)

David M. Bunis (1993: 414-437) detalladamente enumera los nombres del idioma:

Desde la Edad Media hasta nuestros días los sefardíes han utilizado distintos nombres para referirse a su lengua. En el propio idioma la lista incluye nombres más tempranos como romance, lengua vulgar, ladino, y (e)spanyol, a los que se añadieron después hakitía en Marruecos y franko, judezmo, jidyó y judyó, lingwa judía, žudeo-espanyol, žargón y otros en el Imperio Otomano. En el hebreo rabínico utilizado por los hakamim sefardíes a lo largo de la historia del grupo étnico, el idioma ha recibido el nombre de laž az (sefardí). En Israel, se le llama sobre todo spanyolit, ladino y žudeo-espanyol; en otras partes, quizás el término más utilizado a nivel popular sea 'ladino', mientras que quienes estudian el idioma, suelen preferir 'judeo-español' (o su equivalente en otras lenguas) o 'judezmo'. (Ibídem, 415)

Ana Riaño (1993: 85) es casi la única que expone el problema de las diversas denominaciones con una actitud curiosísima:

Sabemos que desde la Edad Media hasta hoy la lengua de los judíos españoles ha recibido diversos nombres. Pero no voy a insistir en esa larga lista de denominaciones de la que ya ha tratado más de un investigador, sino que sólo me detendré en un par de aspectos que atañen al tema. Por un lado, la convivencia de que de todos los nombres dados al sistema lingüístico de los judíos españoles nos inclinemos por el de lengua sefardí, porque, del mismo modo que los españoles decimos que la lengua de los ingleses es el inglés y no el english, o la de los alemanes el alemán y no el deutsch, debemos decir que la lengua de los sefardíes es el sefardí. Y quede, además, como propio de la bibliografía académica española el vocablo judeoespañol.

Después de lo escrito parece que es sensato hablar de la lengua sefardí, el sefardí o usar el vocablo judeoespañol y reservar ladino para la lengua de los textos religiosos. Otras denominaciones son interesantes como muestra de las variantes de esta lengua en que aparece ya el nombre mismo de la lengua.

Las opiniones sobre las denominaciones de la lengua sefardí han cambiado a lo largo del siglo XX, desde las definiciones descriptivas hasta las más elaboradas, críticas y cien- 
tíficas, lo que afirma que también la "sefardología" en los últimos veinte años ha aportado nuevos aspectos sobre el tema.

\section{La cuestión de la llamada "lengua calco"}

Como se ha visto en el capítulo anterior la denominación ladino está muy difundida.

Desde la década de los sesenta la escuela francesa (sobre todo I. S. Révah y H. V. Sephiha) ha atribuido al término ladino un nuevo significado. En el Primer simposio de estudios sefardíes en Madrid (1964) Haim Vidal Sephiha proclamó que el ladino no se habla. Este término lo ha reservado para el español empleado en las traducciones y libros de carácter religioso. Con su tesis titulada Le ladino. Judéo-espagnol calque (1973) presenta la idea sobre el judeoespañol calco. ${ }^{2}$

Calcar significa "copiar o reproducir algo con gran exactitud y servilismo" (Enciclopedia Universal Multimedia, 1999/2000), los sinónimos son: copiar, reproducir, duplicar, trasladar, plagiar, imitar, repetir, y calco significa "copia que se obtiene calcando". (Ibídem) ¿Y qué tiene que ver la denominación ladino con la lengua calco?

Los judíos españoles en la España medieval tradujeron los textos sagrados hebreos al español y fueron adictos a un tipo de traducción servil, porque es bien sabido que no se debe cambiar o transformar de cualquier modo el texto sagrado. Las traducciones al ladino son literales y mantienen todas las características (sobre todo sintácticas) de la lengua original hebrea. A este tipo de traducciones en ladino la escuela de H. V. Sephiha atribuye la denominación de ladino. Sephiha llama el resultado de ese sistema de traducción "lengua calco" o "lengua copia" y para él esa lengua, el ladino, es una lengua diferente de la lengua sefardí normal, que llama judesmo. Con su teoría ha impuesto la diferencia entre dos tipos de judeoespañol, "judeoespañol calco" o ladino y "judeoespañol vernáculo" o judesmo.

Algunas investigaciones más recientes de Iacob M. Hassán, Moshe Lazar e Isaac Jerusalmi comprueban que no se debe llamar ladino únicamente a la traducción calco de textos sagrados en lengua romance, sino a todo ladinamiento, todo lo que fue escrito "en cristiano". Hassán (1995: 129) argumenta la denominación con el hecho de que el ladino con el sentido de técnica de traducción servil no es una lengua diferente, sino un nivel estilístico da la misma lengua.

2 Puesto que la tesis en Eslovenia no es disponible, me he servido de las informaciones sobre H. V. Sephiha de Nezirovic (1992: 118-123) y Alvar (2000: 43). 


\section{Sistemas gráficos}

\subsection{La grafía aljamiada hebraica y su interpretación}

Como los musulmanes que hablaban hispano-romance en la España medieval escribían su lengua con las letras árabes, también los judíos de España para escribir el romance utilizaron el alfabeto hebreo, el alefato, en su forma manuscrita llamada la 'caligrafía rasí'.

La palabra rasí se puede escribir con mayúscula, porque es la sigla de las iniciales de Rabbi Shelomo Ishaki (1040-1105), cuyos comentarios se imprimieron con este tipo de letra. La enciclopedia nos enseña que "rasí es alifato (sic) hebreo de tipos semicursivos, utilizado frecuentemente para escribir textos sefardíes aljamiados". (Enciclopedia Universal Multimedia, 1999/2000)

Aquí hay que subrayar el uso de la palabra aljamía que es el nombre que los moros daban a las lenguas de los cristianos peninsulares y se refiere a los textos en romance, pero transcritos con caracteres arábigos o hebreos. Lo último es especialmente importante para el tema estudiado.

Después de la expulsión, ya fuera de España, los judíos siguieron utilizando la grafía aljamiada, hasta que los hablantes entraron en contacto con el francés, el italiano, el turco moderno, el inglés y el español a finales del siglo XIX y en el siglo XX, y empezaron a escribir su idioma en el alfabeto latino.

En 1928 en Turquía Mustafa Kemal Atatïrk ordenó por ley que la caligrafía árabe tradicional se reemplazara por el alfabeto latino en el turco moderno. Así los judíos empezaron a publicar sus obras en letras latinas.

Es interesante el hecho que en Bulgaria se imprimieron unas pocas publicaciones en alfabeto cirílico búlgaro y en Grecia en alfabeto griego. En Salónica los sefardíes siguieron imprimiendo sus publicaciones en caracteres rasíes tradicionales hasta la Segunda Guerra Mundial, cuando por desgracia se cerraron las imprentas judías de la ciudad.

En Bosnia la lengua sefardí se escribía en aljamía hebraica, pero a partir de 1924 algunas revistas empezaron a utilizar el alfabeto latino, porque había mucha gente que ya no sabía leer los textos aljamiados. Nezirović (1992: 128) anota que también en Bosnia se ha encontrado un documento en que la lengua sefardí está escrita en alfabeto cirílico.

La cuestión que se plantea al leer los textos sefardíes aljamiados es si la grafía de una lengua semítica, que no anota las vocales, puede representar adecuadamente todos los sonidos de una lengua romance. Sin embargo, cedemos la solución de este problema a hebraístas e hispanistas. Efectivamente, la grafía aljamiada es una de las cosas que era común a todos los sefardíes dispersos por el mundo y les servía como medio de comunicación, a pesar de que existían muchas variantes del judeoespañol.

\subsection{Grafias y transcripciones latinadas. Ortografía normalizada.}

Aunque muchos textos sefardíes están escritos en letras latinas, las transcripciones difieren entre sí. Es decir, que los que escriben en la lengua sefardí no tienen un sistema unificado para transcribir la lengua en letras latinas, y que los textos transcritos se distinguen de país en país. 
La transcripción de la lengua sefardí sirve para transcribir, representar por escrito, un discurso oral, por ejemplo la lengua sefardí hablada, o transcribir los textos en aljamía hebraica en caracteres latinos.

De nuevo hay que exponer la dispersión de los sefardíes. Hay que tener en cuenta que la comunidad linguiística sefardí está fragmentada y cada fragmento rodeado de una lengua distinta. Normalmente también esta lengua tiene influencia sobre la elección del sistema de la transcripción de la lengua sefardí.

El hecho de que existen varios sistemas de transcripción (español, francés, hebraico, turco, serbocroata...) queda claro si tomamos un ejemplo de la revista sefardí $A k y$ Yerushalayim (Israel), uno de la revista Vidas Largas (Francia), un drama de Laura PapoBohoreta (Bosnia) o cualquier publicación del Insituto Arias Montano del CSIC (España) y nos damos cuenta de que los sistemas gráficos usados son completamente distintos.

Hassán propone el siguiente sistema gráfico: "Sobre una ortografía basada hasta donde sea posible en la del español normativo, los rasgos diferenciales de la fonética sefardí se representan mediante la adición de puntos, tildes $\mathrm{u}$ otros signos diacríticos a ciertas letras" (Hassán, 1978: 149). Subraya que la grafía de la lengua sefardí dentro de un contexto de la filología hispánica tiene que estar en concordancia con la tradición de lectura del español y así legible y comprensible para un hispanista.

\section{Algunos enfoques del estudio de la lengua sefardí}

Para tener una idea de cómo investigar la lengua sefardí se presentan algunos tipos de enfoques de los que se han aprovechado los investigadores del fenómeno lingüístico llamado la lengua sefardí a lo largo del siglo XX. Al describir los fonemas y sonidos se utiliza la transcripción fonética y la "denominación fonética" de los fonemas según el Alfabeto Fonético Internacional (AFI). ${ }^{3}$

\subsection{Max Leopold Wagner}

Entre 1909 y 1914 Wagner publicó su teoría histórica y lingüística sobre los sefardíes. ${ }^{4} \mathrm{El}$ español hablado por los sefardíes en Oriente fue el de la época de la expulsión, el de fines del siglo XV y de la primera mitad del siglo XVI.

Wagner (1990, tomo III: 123) enumera rasgos arcaicos de la pronunciación del judeoespañol; la conservación de las consonantes sonoras del antiguo español:

- El fonema fricativo alveolar sonoro $/ z /$ entre vocales, el fricativo postalveolar sonoro $/ 3 /$ en lugar del actual fricativo velar sordo $/ x /$, que se distinguen del fricativo alveolar sordo /s/ y del fricativo postalveolar sordo / $/$.

\footnotetext{
${ }^{3}$ Las denominaciones foneticas según Handbook of the International Phonetic Association (1999), la Enciclopedia Universal Multimedia (1999/2000), la voz guía Alfabeto Fonético Internacional e Historia de la lengua española I de Medina López (1999: 53-55).

${ }^{4}$ Su teoría es presentada en varios estudios, los más importantes son: Beiträge zur Kenntnis des Judenspanischen von Konstantinopel (1914), Algunas observaciones generales sobre el judeo-español de Oriente (1923) Caracteres generales del judeo-español de Oriente (1930), y Espigueo Judeo-español (1950), todos reimprimidos en Wagner, M. L., Judenspanisch I, II, en Sondersprachen der Romania III, IV (Stuttgart: Franz Steiner Verlag, 1990).
} 
- La distinción entre el fonema oclusivo bilabial sonoro /b/ y el fricativo bilabial sonoro / $/$ / sobre todo en posición inicial, según la procedencia latina.

- La existencia del grupo /dz/: dodze (doce), tredze (trece).

Wagner también da ejemplos de la morfología, la sintaxis y la fraseología sefardíes con los cuales argumenta "las huellas del arcaísmo" en el sefardí.

Su teoría es la primera que contiene una división regional.

Hablando de los judíos orientales piensa que los sefardíes de Constantinopla y de Asia son, en su mayoría, procedentes de las dos Castillas, mientras que los de Macedonia, de Grecia, Bosnia, Serbia y parte de Bulgaria fueron principalmente oriundos de las provincias de Aragón y Cataluña.

Según Wagner (que vivió tres años en el barrio judío de Constantinopla, Turquía) la tradición oral de los judíos concuerda bastante bien con las condiciones lingüísticas que se pueden observar en la lengua popular de las distintas regiones de Oriente donde se habla el judeoespañol.

El autor distingue dos grupos principales: el occidental (Salónica, Macedonia, Bosnia, Serbia, Bulgaria Occidental) y el oriental (Adrianópolis, Constantinopla, Bursa, Esmirna, Rodas).

Los rasgos principales del grupo occidental son:

- La /o/ final se pronuncia como /u/.

- La /e/ final se pronuncia como/i/,

- La /a/final se pronuncia como una /e/ relajada,

- La conservación del fonema fricativo labiodental sordo /f/ inicial,

- La pronunciación de /e/ como /a/: piarna (pierna), vardi (verde).

Estos rasgos guardan relación con los rasgos de los dialectos de España del norte o de Portugal, es decir, de los dialectos de Asturias, Galicia, Aragón y hasta cierto punto de Cataluña.

Según la teoría las condiciones fonéticas del grupo oriental concuerdan con las de Castilla lo que también argumenta con ejemplos.

Wagner es la primera persona que escribió una teoría sobre los dialectos españoles y la lengua sefardí. Coleccionó y documentó muchos textos en judeoespañol e hizo un vocabulario extenso del habla de los sefardíes de Oriente. Los ejemplos del habla de los judíos en sus publicaciones todavía son de mucha importancia para el conocimiento sobre el judeoespañol y siguen citándose hoy en día en los estudios lingüísticos sobre el tema.

\subsection{Cynthia M. Crews}

Con su trabajo Wagner entusiasmó a la investigadora inglesa Cynthia M. Crews que como él tenía la oportunidad de vivir con familias sefardíes, escuchar, aprender y escribir su lengua. Tuvo suerte porque realizó su investigación sobre los sefardíes en los Balcanes en los años treinta del siglo XX, antes de la Segunda Guerra Mundial. 
En sus viajes por los Balcanes en la primera mitad del siglo XX, Cynthia M. Crews examinó diferentes variantes del judeoespañol entrevistando a los sefardófonos de diferentes ciudades.

En su tesis publicada en $1935^{5}$ presentó las características de la lengua sefardí de Constantinopla, Salónica, Bucarest, Bitola y Skopje. Primero presenta una descripción de las características de la variante estudiada y la compara con otros estudios anteriores de este tipo (de Wagner, Luria, Lamouche, etc.). Como ejemplos del estudio teorético siempre añade textos escritos en la variante examinada. Los textos, fonéticamente transcritos, son sobre todo cuentos y consejas que no sirven sólo para un estudio de la lengua sino ofrecen tambíen muchas posibilidades para un estudio literario.

\subsection{Ana Riaño}

En el artículo La lengua sefardí (1993) Riaño expone las principales peculiaridades que definen la lengua sefardí.

\subsubsection{Carácter arcaico}

La base de esta lengua es el habla castellano-andaluza de los siglos XV y XVI. Algunos de sus rasgos están relacionados con el castellano preclásico, como por ejemplo algunos sonidos que se han mantenido en la lengua sefardí, pero no en el español moderno:

- /S/ fricativo postalveolar sordo

- $/ 3 /$ fricativo postalveolar sonoro

- /dz/africado postalveolar sonoro

- $\quad$ / $/$ / fricativo alveolar sonoro

- la conservación de la diferencia entre el sonido oclusivo bilabial sonoro /b/ y el fricativo bilabial sonoro $/ \beta /$ que a veces se realiza como $/ v /$, fricativo labiodental sonoro

- el mantenimiento de la /f/ latina en posición inicial de palabra

\subsubsection{Peculiaridades innovadoras}

Algunos rasgos han ido más allá de las realizaciones a las que ha llegado el español moderno, como por ejemplo el seseo y el yeísmo.

\subsubsection{Carácter de lengua de fusion}

El judeoespañol es una lengua que combina materiales; tanto los del español medieval: hebreo-arameo, griego y árabe, como de fuentes lingüísticas nuevas con las que los judíos entraron en contacto tras la expulsión: hebreo, árabe, norteafricano, turco, griego, búlgaro, rumano, serbocroata, francés, italiano.

Su descripción de las características principales del idioma es concisa y comprensible.

${ }^{5}$ Crews, C. M., Recherches sur le judéo-espagnol dans les pays balkaniques (Paris: Librairie E. Droz, 1935), Société de publications romanes et françaises XVI. 


\subsection{David M. Bunis}

Bunis (1993: 414-437) hace un repaso de las características del judeoespañol en cada período, siempre con las circunstancias históricas y ejemplos del judeoespañol de los materiales escritos u orales. En la parte final habla de las características del idioma moderno. En este apartado dedica la mayor parte a la estructura compositiva del idioma. Dice que el idioma hablado y escrito por los sefardíes en el período moderno se caracteriza por:

- la preservación de elementos medievales,

- las modificaciones internas y los neologismos,

- las incorporaciones tomadas de las nuevas fuentes lingüísticas que los judíos encontraron tras dejar España.

Según Bunis algunos de los fenómenos característicos del habla de los sefardíes se pueden ejemplificar con la terminología de diferentes esferas del vocabulario. En el estudio expuesto nos ofrece ejemplos de la terminología contemporánea del cuerpo y sus elementos. Aunque Bunis da ejemplos de elementos hispánicos, hebreos y arameos, ejemplos tomados de los idiomas coterritoriales tradicionales, de las lenguas europeas prestigiosas y de algunas variedades regionales, se enumeran aquí sólo algunos ejemplos de elementos hispánicos.

Algunas palabras sefardíes son idénticas a sus equivalentes españoles modernos: dedo, palma, garganta, unya, paladar, frente.

Los preservados fenómenos del sistema de sonidos, gramática y léxico medievales que ya no se encuentran en el español moderno estándar son los siguientes;

- Los sonidos medievales $/ \mathrm{J} /, / 3 /, / \mathrm{d} z /$ se conservan: kišada (en español antiguo quixada, en español moderno quijada), ožo (ojo).

- El fonema fricativo labiodental sordo /f/ inicial se conserva intacto: figado/- $u$ (hígado), fyel (fiel).

- La preservación del fonema oclusivo bilabial sonoro /b/ y el fricativo labiodental sonoro /v/ como fonemas distintos: bokal (bocal), vokal (vocal).

- Se conserva el grupo de consonantes medievales /vd/: kovdo (codo).

- Se conserva el grupo de consonantes medievales $/ \mathrm{mb} /$ : lombo (lomo, espalda).

- Se conserva el grupo de consonantes medievales $/ \mathrm{k} /$ : $k a s ̌ k o$ (casco).

En el transcurso de los siglos los sefardíes en el Imperio Otomano y en el norte de África modificaron algunos de los elementos hispánicos que habían llevado de España;

- $\mathrm{El} / \mathrm{we} /$ inicial se resulve en /gwe/: gweso (hueso).

- La eliminación de la /e/ inicial cuando va seguida de /s/ + consonante: spalda (espalda).

- La metátesis del grupo consonante $/ \mathrm{rd} />/ \mathrm{d} /$ godro (gordo).

En lo que concierne la gramática, también hay varias diferencias entre el habla judía y el español cristiano:

- Los sefardíes otomanos utilizan los sufijos diminutivos -iko y -eziko en vez de los usados por españoles -illo e -ito: dediko (dedillo), manezika (manita). 
- En el habla judía las palabras y los sufijos de origen hispánico, se combinan a veces para formar nuevas palabras: pecho + la terminación para formar nombres abstractos -adura: pečadura (seno, regazo).

Bunis distingue perfectamente las distintas "influencias" sobre la lengua sefardí y las argumenta de una manera innovativa y atractiva.

\subsection{Ralph Penny}

Hablando del judeoespañol en La innovación fonológica del judeoespañol (1992), Dialect Contact and Social Networks in Judeo-Spanish (1992), y Variation in JudeoSpanish (2000) también Penny trata de explicar la cuestión de los dialectos. La vieja convicción de que el judeoespañol es una mezcla de dialectos le parece imprecisa porque le falta una teoría adecuada para argumentarla.

Penny formula dos premisas; la primera de que los judíos provenientes de distintas partes de la Península hablaban de distinta manera antes de 1492 (la cual no abarca el problema de hasta qué punto el habla de los judíos difería de la de los cristianos), y la segunda, según la que las redes sociales que unían a los judíos antes de 1492 se trastornaron profundamente a raíz de la expulsión.

En su opinión el concepto del judeoespañol como 'mezcla de dialectos' no explica la razón por la que algunos elementos de la mezcla sobreviven y otros desaparecen. Penny argumenta sus ideas apoyándose en la teoría de contacto de dialectos y la de las redes sociales.

Primero presenta la teoría de contacto de dialectos del sociolingüista inglés Peter Trudgill (Penny, 1992: 126-134) con la que argumenta su premisa y enumera los elementos no castellanos del judeoespañol. Mencionemos aquí sólo los más frecuentes:

- El yeísmo: kaye (calle), yamar (llamar), streya strea (estrella), eya ea (ella).

- El seseo : pasar (en español medieval passar), piesa (en español medieval pieça).

- El zezeo: kaza (casa), kuzina (en español medieval cozina).

- El grupo $/ \mathrm{mb} /$ en vez de $/ \mathrm{m} /$ : lamber (lamer), lombu (lobo), palomba (paloma).

- Variantes diptongadas y no diptongadas: prieto $-u$ / preto $\sim u$ (prieto), ruego -u / rogo -u (ruego).

- Los distintos resultados de la /f/ inicial latina: furmiga urmiga (hormiga), fieru ieru (hierro).

Basándose en el trabajo sociolingüístico de James y Lesley Milroy y otros sobre las redes sociales y sus efectos lingüísticos, argumenta su segunda premisa, con la conclusión de que según la teoría de las redes sociales en el caso del judeoespañol vemos la innovación lingüística en los primeros tiempos de la expulsión. Penny enumera las innovaciones:

- La palatalización de la /a/ final en /e/: kaze (casa), meze (mesa).

- La pérdida de la /e/ inicial seguida de/s/ + consonante: skalera (escalera), skrivir (escribir), spada (espada), spantarse (espantarse). 
- La convergencia total de los fonemas vibrante simple alveolar sonoro, y /r/, vibrante múltiple alveolar sonoro, con pérdida del vibrante: enterarse (enterrarse), fieru ieru (hierro).

- Cambio del nasal alveolar sonoro $/ \mathrm{n} /$ inicial en nasal bilabial sonoro $/ \mathrm{m} /$ muzotros (nosotros), mos (nos), muestro (nuestro).

- La cerrazón de la /e/ final en /i/: esti (este), esi (ese), tardi (tarde), nochi (noche).

- Ante diptongo $/ \mathrm{we} /, / \mathrm{n} /$ cambia en $/ \mathrm{m} /$ muevi (nueve), muevu (nuevo), muez (nuez).

- La metátesis de /rd/ en /dr/: akudrarsi (acordarse), godru (gordo), pidrer (perder), pidrunar (perdonar), tadri (tarde), vedri (verde).

Las innovaciones expuestas "no se observan en ninguna otra variedad del romance hispánico" (Penny, 1992: 255) y Penny las considera debidas al trastorno de las redes sociales a consecuencia de la expulsión de 1492. Su opinión es totalmente opuesta a la convicción tradicional sobre el judeoespañol profundamente conservadora.

El reciente estudio de Penny es un ejemplo que afirma la importancia del trabajo interdisciplinario. Con una teoría sociolingüística contemporánea ha explicado la cuestión de dialectos de una perspectiva nueva e interesantísima.

\section{Conclusión}

Es imposible hablar sobre cuándo nace o muere una lengua. La lengua sefardí todavía no está muerta porque todavía existen "sefardohablantes". Son pocos y no se puede precisar cuántos son.

El último párrafo de todos los estudios sefardíes está dedicado a la extinción de la lengua estudiada. Es evidente que casi ha desaparecido, sin embargo, en los últimos veinte años ha crecido el interés por la lengua y literatura sefardíes y podemos hablar de un renacimiento de los temas sefardíes. Esperemos que con este párrafo no desaparezcan los estudios sobre la lengua sefardí hoy y mañana, si es que hay un mañana para la lengua sefardí.

\section{Bibliografia}

Alvar, M., El ladino, judeo-español calco. Real Academia de la Historia, Madrid, 2000.

Baruch, K., "El judeo-español de Bosnia", Revista de Filología Española, Madrid, 1930, XVII, 2, 113-154.

Bunis, D. M., "El idioma de los sefardíes: un panorama histórico" en Morešet Sefarad: El legado de Sefarad, Editorial Universitaria Magnes, Jerusalén, 1993, vol.II, 414-437.

Crews, C. M., Recherches sur le judéo-espagnol dans les pays balkaniques. Librairie E. Droz, Paris, 1935.

Enciclopedia Universal Multimedia @Micronet S.A. 1999/2000.

Handbook of the International Phonetic Association. Cambridge University Press, CambridgeNew York-Melbourne, 1999. 
Hassán, I. M., "El español sefardí (juđeoespañol, ladino)" en La lengua española hoy. Fundación Juan March, Madrid, 1995, 117-140.

Hassán, I.M., "Transcripción normalizada de textos judeoespañoles" en Anejo de Estudios Sefardies 1, 1978, 147-150.

Knezović, A., Fonetika i fonologija židovsko-španjolskog govora u Sarajevu, magistarski rad. Filozofski fakultet sveučilišta u Zagrebu, Sarajevo, 1986.

Knezović, A., "Unas características específicas del judeo-español de Sarajevo, Bosnia", en Verba Hispánica 1. Filozofska fakulteta, Ljubljana, 1991, 97-103.

Lleal, C., El judezmo: el dialecto sefardí y su historia. PPU, Barcelona, 1992, 1-82.

Medina López, J., Historia de la lengua española I - Español medieval. Arco Libros, Madrid, 1999. Nezirović, M., Jevrejsko-španjolska književnost. Institut za književnost, Svjetlost, Sarajevo, 1992. Penny, R., "Dialect Contacts and Social Networks", Romance Philology, 46, 1992-93, 125-140.

Penny, R., "La innovación fonológica del judeoespañol" en Actas del II Congreso Internacional de Historia de la lengua española. Pabellón de España, Madrid, 1992, vol. II , 251-257.

Penny, R., "Variation in Judeo-Spanish" en Variation and change in Spanish, Cambridge University Press, Cambridge, 2000, 174-193.

Riaño, A., "La lengua sefardí y su evolución", en Actes del Simposi internacional sobre cultura sefardita. PPU, Barcelona, 1993, 83-105.

Wagner, M. L., "Judenspanisch I, II", en Sondersprachen der Romania III, IV. Franz Steiner Verlag, Stuttgart, 1990.

\section{PROBLEMI PROUČEVANJA SEFARDSKEGA JEZIKA}

Sefardski jezik oziroma judovska španščina se je kot materni jezik Judov (tako imenovanih Sefardov), izgnanih iz Španije 1492, ohranil več kot štiristo let, vse do danes. V bližnji prihodnosti bodo umrli njegovi zadnji govorci in jezik bo izginil. Prispevek je oris problemov, ki se pojavljajo pri raziskovanju sefardskega jezika. Govori o njegovem razvoju, glavnih značilnostih in posebnostih ter različnih pristopih, ki so se jih nekateri hispanisti lotili pri študiju sefardskega jezika v 20. stoletju. 